Volume: 3

Issue: 1

Page: $1-8$

November 2016

\title{
Comparison of VieVS and Solve UT1 results from VLBI measurements
}

\author{
Minttu Uunila ${ }^{1, *}$, Karen Baver², John Gipson², Tobias Nilsson³, Hana Krásná4 \\ ${ }^{1}$ Aalto University Metsähovi Radio Observatory, Metsähovintie 114, 02540 Kylmälä, Finland \\ ${ }^{2}$ NVI Inc., 7257D Hanover Parkway, Greenbelt, Maryland 20770, USA \\ ${ }^{3}$ Helmholtz Centre Potsdam, GFZ German Research Center for Geosciences, Telegrafenberg, 14473 Potsdam, Germany \\ ${ }^{4}$ Technische Universität Wien, Department of Geodesy and Geoinformation, Gusshausstrasse 27-29, 1040 Vienna, Austria
}

\section{Abstract}

Comparison of different geodetic VLBI analysis software packages is highly important to ensure that they work properly. Two of the data software packages used by the geodetic VLBI community are Solve and the Vienna VLBI Software (VieVS) packages. In our study we investigate UT1 estimates from VieVS and Solve for both 1-hour IVS Intensives and 24-hour R1s and R4s with various configurations. We synchronized the settings of the two software packages as much as possible without extensive software changes. In this configuration the weighted mean difference of the UT1 estimates from the IVS intensives was $7.8 \mu$ s with a WRMS scatter of $7.1 \mu \mathrm{s}$. The weighted mean difference for the 24-h sessions was -1.7 $\mu$ s with a WRMS scatter of $5.5 \mu$ s. We also investigated the effect of changing other aspects of the solution configurations. In general the resulting differences were small except for imposing a tight clock constraint which significantly worsened the solutions.

Keywords

VLBI, IVS, UT1, Earth rotation

\section{Özet}

\section{VLBI Ölçümlerinden elde edilen VieVS ve Solve UT1 Sonuçlarının Karşılaştırılması}

Cilt: 3

Sayı: 1

Sayfa: $1-8$

Kasım 2016
Farklı jeodezik VLBI analiz yazılım paketlerinin karşılaștırılması, bu paketlerin düzgün çalıștıklarından emin olunabilmesi için son derece önemlidir. Viyana VLBI Yazllımı (VieVS) ve Solve, Jeodezik VLBI topluluğu tarafindan kullanılan iki farklı veri yazılım paketidir. Çalışmamızda VieVS ve Solve'dan çaşitli konfigürasyonlarla elde edilen 1 saatlik IVS yoğun ve 24 saatlik RIs ve R4s UT1 ölçüleri incelenmektedir. İki yazılım paketinin ayarları mümkün olduğunca kapsaml yazılım değişiklikleri yapılmadan senkronize edilmiştir. Bu konfigürasyonda, yoğun IVS UT1 ölçülerinin ağırlıklı ortalama farkı 7.1 ps'lik ağırlıklı karesel ortalama (WRMS) yayılımı ile $7.8 \mu$ s'dir. 24 saatlik ölçülerin ă̆ırlıklı ortalama farkı $5.5 \mu$ s'lik ağırlıklı karesel ortalama (WRMS) yayılımı ile -1.7 $\mu$ s'dir. Ayrıca çözüm konfigürasyonlarının diğer yönlerinin değişmesinin etkileri incelenmiştir. Sonuçları önemli ölçüde kötüleştiren sıkı saat kısıtlamalarının eklenmesi dışında genellikle sonuçların farkları küçüktür.

Anahtar Sözcükler

VLBI, IVS, UT1, Yer dönüklüğü 


\section{Introduction}

In this study we compare ERP estimates from IVS sessions devoted to measuring Earth Rotation Parameters (ERP) from two software packages. From a practical point of view the ERP are important in spacecraft navigation, e.g., GPS satellite navigation. From a scientific point of view, changes in the ERP are due to geophysical effects, and measurements of changes in ERP put constraints on various geophysical models.

The Solve analysis software (Ma et al. 1990) is widely used by the geodetic VLBI community. One of the newer software packages is the Vienna VLBI Software (VieVS, Böhm et al. 2009). VieVS is written in Matlab and based loosely on OCCAM (Titov et al. 2004). The computed delays and partial derivatives of the software packages VieVS, Solve, C5++ (Hobiger et al. 2010), SteelBreeze (Bolotin 2000) and OCCAM were compared by Plank et al. (2010) and Plank (2010). Our research extends the studies done by Plank et al. by concentrating in particular on VieVS and Solve comparison, by synchronizing the configurations of the two software packages, modifying VieVS, and studying the effect of single parameter changes on the results.

We compared the UT1 estimates from the two packages for 1-hour IVS Intensives and 24-hour IVS-R1 and IVS R4 sessions (Schuh and Behrend 2012). We extend the comparison started by Uunila et al. (2012) by using a larger data set, introducing baseline dependent weights to VieVS, using mid-session epochs also in VieVS and by giving special attention to two VLBI stations affected by major earthquakes prior to the epoch of the data used in this paper: the Tsukuba, Japan 32-meter diameter VLBI antenna (TSUKUB32), and the transportable 6-meter diameter VLBI antenna at Concepcíon, Chile (TIGOCONC). The effects of altering the atmosphere mapping function, clock constraint, an a priori EOP file, and turning off atmospheric pressure loading were examined individually to see the magnitude of changing a single parameter. Böhm and Schuh (2007) investigated the effect of changing a mapping function on 1-hour session UT1 results. But they did not examine UT1 results from 24-h sessions nor the other single parameter changes, on which this article also concentrates.

Section 2 describes the configuration of the software packages, their similarities and differences, and modifications done for VieVS. In Sect. 3, we describe the analysis configuration, data sets and analysis strategy. Results are shown in Sect. 4. Finally, conclusions are presented in Sect. 5 .

\section{Configuration of the software packages}

In our study we used VieVS version 2.2, and Solve release 2014.02.21. Both software packages have very flexible configurations, and the results from the packages depend on the selected configuration settings. In this section we discuss these issues.

\subsection{Default Configuration}

\subsubsection{Description}

As an initial test we ran both software programs using their default settings, summarized in Table 1, and separately compared estimates of UT1 for 24-h sessions and UT1 for Intensives. Default settings in this context means that the set of models and files used by the software packages is the same as the one used when performing regular analysis of the two types of sessions. The models, input files and epochs differ depending on whether you are using VieVS or Solve, and whether you are analyzing Intensives or $24-\mathrm{h}$ sessions. The default solution is not truly the default because having the same a priori EOP series so strongly affects the results that it is important to use the same a priori. All our solutions used USNO's finals2000A data file, except for one of the single change solutions, which used IERS C04 08 to test the effect of the change to the EOP a priori file.

\subsubsection{Comparison (Similarities and Differences)}

As is seen in Table 1, the two software packages are very similar. In this section we elaborate on the differences between them. We follow the order of Table 1.

Table 1 : The default configurations of VieVS and Solve are very similar. Differences are described in the text.

\begin{tabular}{|c|c|c|}
\hline & Default Configuration of VieVS and Solve & \\
\hline Software & VieVS & Solve \\
\hline $\begin{array}{l}\text { Solution type } \\
\text { Number of sessions } \\
\text { Ephemerides } \\
\text { Pressure loading } \\
\text { A priori EOP } \\
\text { Precession/nutation } \\
\text { TRF } \\
\text { CRF } \\
\text { Weighting } \\
\text { Mapping function } \\
\text { ZWD interval, constraint } \\
\text { Clock interval, constraint } \\
\text { UT1 interval, constraint } \\
\text { Epoch }\end{array}$ & $\begin{array}{l}\text { Group delay only } \\
\text { One standalone } \\
\text { JPL } 421 \\
\text { Petrov and Boy (2004) } \\
\text { finals } 2000 A \\
\text { IAU } 2006 \\
\text { VTRF2008 } \\
\text { Except for earthquakes } \\
\text { ICRF2 } \\
\text { a constant value of } 33 \text { ps }(1 \mathrm{~cm}) \text { is } \\
\text { added to each observation error } \\
\text { VMF1 } \\
\text { Int: one offset per station, no constraints } \\
\text { 24-h: } 30 \text { min, } 3.0 \mathrm{~cm} / \mathrm{h} \\
\text { Int: one offset and a rate, no constraints } \\
24-h: 60 \text { min, } 1.3 \mathrm{~cm} / \mathrm{h} \text {, piece-wise linear } \\
\text { (PWL) offsets } \\
\text { Int: one offset, no constraints } \\
24-h: \text { one offset, no constraints } \\
\text { midnight }\end{array}$ & $\begin{array}{l}\text { Group delay only } \\
\text { Int: One standalone } \\
24-\mathrm{h} \text { : combined solution } \\
\text { JPL } 421 \\
\text { Petrov and Boy (2004) } \\
\text { finals } 2000 \mathrm{~A} \\
\text { IAU } 2006 \\
\text { operational solution output } \\
\text { Except for earthquakes } \\
\text { operational solution output } \\
\text { Baseline weights from a priori solution } \\
\text { VMF1 } \\
\text { Int: one offset per station, no constraints } \\
24-\mathrm{h}: 20 \text { min, } 0.15 \mathrm{~cm} / \mathrm{h} \\
\text { Int: no constraints, a } 2{ }^{\text {nd }} \text { order polynomial } \\
24-\mathrm{h}: 60 \text { min, } 0.54 \mathrm{~cm} / \mathrm{h} \text {, offset, rate, } \\
2^{\text {nd }} \text { order term } \\
\text { Int: one offset, no constraints } \\
24-\mathrm{h} \text { : offset and rate, } 3 \mathrm{~ms} / \mathrm{d} \\
\text { mid-session }\end{array}$ \\
\hline
\end{tabular}


The ERP estimates depend crucially on having good a priori station positions. The VLBI station positions of TIGOCONC (Concepcíon, Chile), and TSUKUB32 (Tsukuba, Japan) were affected by strong earthquakes. After the February $27^{\text {th }}, 2010 \mathrm{M} 8.8$ earthquake TIGOCONC was displaced more than 3 meters in the East direction (Engelhardt et al. 2011). In the M9.0 Tohoku earthquake on March $11^{\text {th }}, 2011$, the UEN displacement of the TSUKUB32 antenna was $90 \mathrm{~mm}$, $640 \mathrm{~mm}$, and $44 \mathrm{~mm}$ (MacMillan et al. 2012). Because of this these stations were treated specially in Solve and VieVS.

In processing 24-h or Intensive sessions, Solve normally uses the a priori TRF from the most recent Solve TRF solution with the exception of TRF datum stations that have recently experienced Earthquakes. In the latter case the station positions of TSUKUB32 and TIGOCONC are estimated on a session-by-session basis in the 24-h sessions. For the Intensive sessions involving TSUKUB32 Solve uses an a priori position based on GPS measurements prior to the epoch of the session. VieVS uses VTRF2008 as a priori TRF, except for stations where an earthquake occurred after this epoch. In a case like this VieVS gets the coordinates from a 'superstation file' which contains an a priori model for the station coordinates. For consistency in the Synchronized configuration, both Solve and VieVS assumed that these stations evolved linearly using the parameters calculated from VieVS data from 2012.

VieVS uses source positions given in ICRF2. Solve normally uses the CRF from the most recent Solve CRF solution. For the vast majority of sources there is little difference between their position in this solution and ICRF2. In a few cases the difference is large because the source position was not well known in ICRF2 because of a limited number of observations. These sources are not used in scheduling of standard geodetic sessions, and hence the effect of using the latest Solve CRF is expected to be small.

In its default configuration VieVS uses global weighting and Solve uses baseline-dependent weighting. Besides, Solve has the option to use global, baseline and site-dependent weighting. Weighting will be discussed in more detail in Section 2.2.

In VLBI analysis it is customary to model the tropospheric delay as a sum of three terms: 1.) The hydrostatic delay; 2.) The wet delay which is caused by water vapor in the atmosphere; and 3.) A gradient term which accounts for an atmospheric tilt. The hydrostatic and wet delay are modeled as the product of a zenith delay times an elevation dependent mapping function. The zenith hydrostatic delay is computed based on the Saastamoinen model (Saastamoinen 1972, Saastamoinen 1973). The zenith wet delay is estimated as a Piece-Wise-Linear (PWL) function, typically with rate-breaks every 20-60 minutes. At higher elevations both the hydrostatic and wet mapping functions behave like $1 /$ sin(elevation angle). At lower elevations the functional dependence is more complicated and is usually given in terms of a continued fraction. Much work has gone into deriving the correct mapping function and in this work we look at the effect of using different ones.

In Intensive solutions ZWD is treated identically in both software packages. In 24-h solutions the ZWD constraints differ.

In VieVS Intensive solutions a clock offset and a rate between clocks are estimated. Solve's estimation of clocks is similar. In Intensive solutions Solve estimates an offset, rate and second order term. The additional parameter eliminates one degree of freedom, making it slightly harder to estimate sessions with pathologically low numbers of observations, which can easily occur with data loss, given that some Intensive sessions are only scheduled to observe $\sim 18$ observations.

For 24-h sessions, VieVS and Solve both use PWL clock parameterization with a 60 minute estimation interval, but their constraints differ a bit. The VieVS relative constraint is $1.3 \mathrm{~cm} / \mathrm{h}$, i.e., loose. The default Solve constraint for the Intensives is $180 \mathrm{ps} /$ hour which is equivalent to $0.54 \mathrm{~cm} /$ hour.

In Intensive solutions both packages estimate an unconstrained UT1 offset. In 24-h solutions VieVS estimates one offset per sessions as default, where as Solve estimates an offset and a rate with a constraint of $3 \mathrm{~ms} /$ day.

We note that resolving all the differences between the two software packages is outside the scope of this study. We want to focus on the effect of changing configuration settings on UT1 estimates without significant modifications to the software packages.

\subsection{Modifications to the VieVS package}

It is well known that in processing VLBI data $\chi^{2}$ is usually larger than 1 , with a typical value being in the range of 4-8. This is symptomatic of either too small measurement errors or of mismodeling the data. One approach to this problem is to "reweight" the data by increasing the errors of the observation in an effort to make $\chi^{2} \sim 1$ (Gipson et al. (2008)).

$\sigma_{t, i, j, o b s}^{2}=\sigma_{t, i j, \text { meas }}^{2}+\varepsilon_{t, i j, w}^{2}$

where $\sigma^{2}{ }_{t, i j, \text { meas }}$ is the measurement noise on baseline $i j$ at time $t, \varepsilon^{2}{ }_{t, i j, i, w}$ is the re-weight constant and $\sigma^{2}{ }_{t, i, j, o b s}$ is their sum. There are three common ways to add noise:

- Global re-weights, which are the same for all observations;

- Station re-weights, which depend only on the stations in an observation;

- Baseline re-weights, which only depend on the baselines in an observation.

In Solve's operational solutions baseline dependent weights are applied as default. VieVS uses a constant weight, i.e., global weighting, and adds a constant weight of 33 ps $(1 \mathrm{~cm})$ to each observation error. To enable more similar configurations of the software packages we incorporated baseline dependent weighting into VieVS, using an iterative process in which the least-squares adjustment is run a second time after calculating the re-weights for each baseline in an observation. We calculated baseline length repeatability from the analysis of CONT08 campaign with three different weighting schemes (Figure 1): the original VieVS weighting, using the weight files from Solve, and the newly implemented baseline dependent weighting. The aim of the CONT08 campaign (Schuh and Behrend 2012) was to acquire state of 


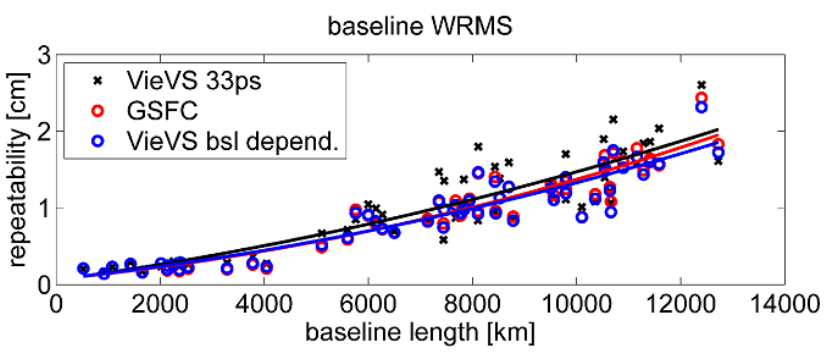

Figure 1: Baseline length repeatability from CONT08 campaign obtained from original version of VieVS (VieVS 33 ps), a version using weight files created with Solve (GSFC), and a new version using baseline dependent weights (VieVS bsl depend.).

the art VLBI data over a two-week period to demonstrate the highest accuracy of which VLBI is capable. In addition, it supported high resolution Earth rotation studies. 11 stations world wide allotted observing time for the 15 session days of the CONT08 campaign.

Baseline repeatability in VieVS is significantly improved when each observation is weighted by baseline dependent constants as opposed to a global constant. An improvement in the weighted RMS (WRMS) was seen in $64 \%$ of the baselines, when we used weight files created with Solve. When we used baseline dependent weights derived from VieVS, the WRMS was reduced in $71 \%$ of the baselines. The effect is larger with longer baselines. The use of baseline weighting also reduces the discrepancy between the UT1 estimates of VieVS and Solve in the Intensive solutions as shown in Figure 2 and Table 4. For the analysis we used the IVS INT1 sessions (Schuh and Behrend 2012) from 2012. The INT1 Intensives are run Monday to Friday and use Kokee Park, USA, and Wettzell, Germany.

\subsection{Handling Earth Orientation Parameter a Prioris}

Both VieVS and Solve allow flexibility in the setting of Earth Orientation Parameter (EOP) a prioris. VieVS requires the a prioris to be input through a file, and allows two standard choices, the IERS C04 file or USNO's finals2000A.data file. The latter file, which is updated weekly, contains Earth orientation data since January 1, 1992, with one year of predictions (USNO Toshi web site 2014). VieVS also allows users to substitute their own file in the format expected by VieVS. VieVS interpolates values from the a priori to the epoch of the observation, using either a linear or a Lagrange interpolation. We use Lagrange, which is the default.

Solve also allows the user to specify any a priori EOP file in the format expected by Solve. If no a priori file is specified, Solve will use the EOP values in the input session data file, but this usage is very rare. As documented in Petrov and Baver (2008), Solve interpolates values from the input a priori to the epoch of each observation. Solve allows the choice of linear interpolation, cubic polynomial interpolation, or cubic spline interpolation with free ends. Solve and VieVS can ignore or take into account UT1 zonal tide variations. Solve and VieVS use zonal tide variations from one of two models, "UT1R" (Yoder et al. 1981) or "UT1S" (Dickman 1993). If a model is used, Solve subtracts the differences (UT1RUT1 or UT1S-UT1, as appropriate), from the a priori file before interpolation, then adds the differences back in after interpolation. In our study Solve used the UT1S model and cubic spline interpolation with free ends for the UT1 estimation. VieVS used Lagrange interpolation. VieVS also applies variations of UT1 caused by zonal tides using the model in Chapter 8 of the IERS 2010 Conventions (Petit and Luzum 2010). This is a combination of Yoder et al. (1981) elastic body tide, Wahr and Bergen (1986) inelastic body tide, and Kantha et al. (1998) ocean tide models.

Because this paper uses the Earth Orientation values produced by VieVS and Solve as the metric for comparison, the authors made the Earth Orientation a priori values consistent for all solutions. The solutions used USNO's finals2000A. data file; except in one single parameter change solution, in which the C04 08 EOP series was used as the a priori series to test the effect of the substitution. The Solve EOP a priori files have some differences with respect to the VieVS files; they have a different format and an additional significant digit. We developed a software to convert the VieVS values to the Solve format.

\section{Analysis Configuration}

\subsection{Data Sets}

We compared solutions from VieVS and Solve using two different data sets designed specifically to measure ERP. Our first data set is the 1-hour Intensives from 2012 with 12 or more observations. We also looked at the INT1 subset of the Intensives. The INT1s are run on Monday-Friday and use the Kokee Park, USA, and Wettzell, Germany VLBI stations. Hence these form a large, homogenous data-set in themselves. Our second data set is the set of R1 and R4 sessions from 2012 with the exclusion of a few pathological cases with large UT1 formal errors. The "1" and "4" indicates sessions that start on Mondays and Thursdays, respectively. Each network for the R1 and R4 sessions has approximately eight stations. There is a core network for each day plus one or two other stations.

For both data sets we looked at the Weighted Mean (WM) and Weighted RMS (WRMS) difference of the UT1 estimates from the two software packages calculated using the formulas:

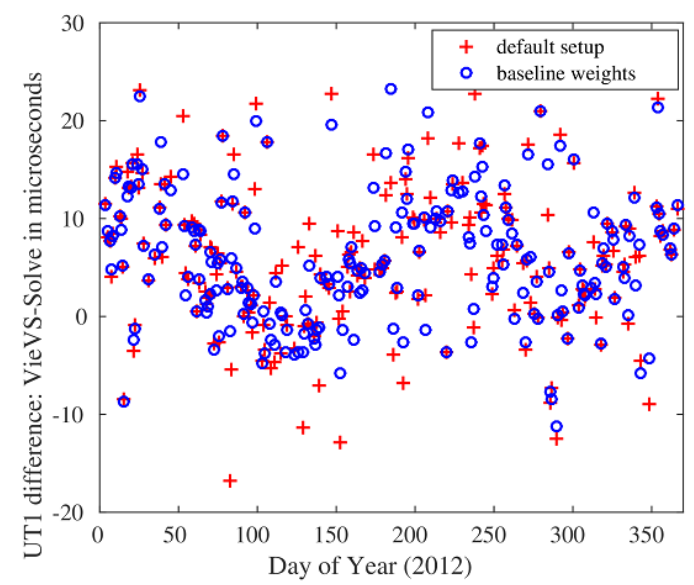

Figure 2: VieVS - Solve UT1 differences from the solutions of INT1 Intensive sessions. VieVS was first run in its Default setup, and then with baseline dependent weighting, and using mid-session epoch. 


$$
W M=\frac{\sum_{i=1}^{N} \frac{\mathrm{UT1}_{\text {VieVS }, i}-\mathrm{UT}_{\text {Solve }, \mathrm{i}}}{\sigma_{\text {VieVS }, i}^{2}+\sigma_{\text {Solve }, i}^{2}}}{\sum_{i=1}^{N} \frac{1}{\sigma_{\text {VieVS }, i}^{2}+\sigma_{\text {Solve }, i}^{2}}}
$$

$$
W R M S=\sqrt{\frac{\sum_{i=1}^{N} \frac{\left(\mathrm{UT}_{\text {VieVS }, i}-\mathrm{UT}_{\text {Solve }, i}-W M\right)^{2}}{\sigma_{\text {VieVS }, i}^{2}+\sigma_{\text {Solve }, i}^{2}}}{\sum_{i=1}^{N} \frac{1}{\sigma_{\text {VieVS }, i}^{2}+\sigma_{\text {Solve }, i}^{2}}}}
$$

$\mathrm{UT}_{1 \mathrm{VieVS}, \mathrm{i}}$ and UT1 $1_{\text {Solve,i }}$ are the estimates of the UT1 from VieVS and Solve analysis, respectively, and $\sigma_{\text {VieVS,i }}^{2}$ and $\sigma^{2}{ }_{\text {Solve, }}$ denote their formal uncertainties. The results are shown in Table 4, and discussed further below. We also examined how much each of the estimates of UT1 differ from the a priori UT1 series which is derived from combining the results of several techniques. We take this a priori as a proxy for the "true" UT1. We do this separately for the VieVS and the Solve solutions. These results are shown in Tables 5-7.

\subsection{Analysis Strategies}

We ran three sets of solutions: Default, Synchronized and Single Change as described in Table 2. Initially each software package was run using the Default solution shown in Table 1. Then a pair of solutions was run to eliminate three major discrepancies: VieVS used baseline weighting to match Solve's weighting scheme, mid-session epoch was used also in VieVS and both packages used the TIGOCONC and TSUKUB32 coordinates described in Section 2.1.2. We call these solutions Synchronized. Subsequently the Synchronized solutions were changed, one aspect at a time, keeping all other aspects the same in order to study the affect of solution setup on UT1 estimates. The four alterations to the synchronized setup were: 1) changing the default mapping function to the Global Mapping Function, GMF (Böhm et al. 2006b), in VieVS or to the Niell Mapping Function, NMF (Niell 1996), in Solve, (due to the use of different mapping functions, the WRMS difference is excluded fromTable 4); 2) changing the a priori EOP file to C04 08; 3) changing the clock constraint option: using the default VieVS constraint for 24-h sessions for Intensives, and using a very weak constraint for 24-h sessions; 4) turning off atmospheric pressure loading. The alterations were applied to both types of sessions, the Intensive and the 24-h sessions. The changes and the results are listed in Table 4-7. Both default and new clock constraints used in the comparison analysis are listed in Table 3.

\section{Results}

\subsection{Default and Synchronized Solutions}

Table 4 displays the difference between VieVS and Solve estimates of UT1. The results from the Default setup are shown in the first data row of Table 4. The WRMS between VieVS and Solve solutions for the Intensives in 2012 and INT1 sessions is $8.8 \mu \mathrm{s}$ and $7.4 \mu \mathrm{s}$, respectively. This compares well
Table 2: Three different solution setups in VieVS and Solve used in the analysis.

\section{Solution Setups in VieVS and Solve}

Default

Both software packages use their default setup as shown in Table 1

VieVS is modified to use Baseline weights and mid-session epochs.

Solve and VieVS use the positions of TIGOCONC and TSUKUB32 derived from a VieVS solution.

Single Change Solutions.

All single change solutions are done with respect to the Synchronized solution. The identifier indi-

\begin{tabular}{|c|c|}
\hline Mapping Function & $\begin{array}{l}\text { Mapping Function VieVS uses GMF mapping } \\
\text { function. Solve uses NMF mapping function. }\end{array}$ \\
\hline EOP & VieVS and Solve use C04 08 as EOP a priori. \\
\hline Clock Constraint & $\begin{array}{l}\text { For the 24-h solutions both VieVS and Solve use } \\
\text { a constraint of } 0.1 \mathrm{~cm} / \mathrm{h} \text {. } \\
\text { For the Intensives both VieVS and Solve use a } \\
\text { constraint of } 1.3 \mathrm{~cm} / \mathrm{h} \text {. }\end{array}$ \\
\hline $\begin{array}{l}\text { No atmosphere or } \\
\text { ocean loading }\end{array}$ & $\begin{array}{l}\text { No atmosphere or Neither VieVS nor Solve use } \\
\text { atmosphere or ocean loading. }\end{array}$ \\
\hline
\end{tabular}
cates what was changed.

with the formal errors (see Table 5 and 6) which are around $13 \mu \mathrm{s}$ and $14 \mu \mathrm{s}$, respectively. The WM of UT1 differences between solutions for all Intensives observed in 2012 and INT1 is $13.7 \mu \mathrm{s}$ and $3.6 \mu \mathrm{s}$, respectively. The WM for the Intensive data set is larger because in the Default solution VieVS and Solve use different a priori positions for Tsukuba. Differences in the East-West components will directly affect the estimate of UT1.

The second data row in Table 4 displays the differences for the Synchronized solution. The WRMS of UT1 differences between VieVS and Solve for all Intensives and INT1 are $7.1 \mu \mathrm{s}$ and $5.2 \mu \mathrm{s}$, respectively. The formal errors are $\sim 13 \mu \mathrm{s}$, and $14 \mu \mathrm{s}$, respectively. Note that again the scatter of WRMS of the INT1 sessions is less than that of the full Intensive sessions. For the Intensive sessions, synchronizing the solutions results in a large reduction of the WM from $13.7 \mu$ s to $7.8 \mu \mathrm{s}$. In contrast the UT1 difference WM for the INT1 sessions increases from $3.6 \mu$ s to $6.0 \mu \mathrm{s}$.

For the 24-h sessions, the difference between the Default and Synchronized solutions is modest. The magnitude of UT1 difference WM decreases from $-2.1 \mu$ s to $-1.7 \mu$ s, while the UT1 WRMS increases from $5.1 \mu$ s to $5.5 \mu \mathrm{s}$. We do not regard these differences as significant. Note the formal error for the 24-h solutions is $\sim 3.5 \mu$ s for VieVS and $2.8 \mu$ s for Solve. Hence the scatter is larger than expected based on the formal errors, indicating that there is room for further improvement.

The first two lines of Tables 5, 6 and 7 compare the Default and Synchronized solutions with respect to $\mathrm{C} 04$ for the Intensive, INT1 and 24-h sessions. For all of these data sets when compared against C04 08 there is not much difference between the Default and Synchronized solutions.

Table 3 : Clock constraints used in the analysis given in $\mathrm{cm} / \mathrm{h}$ for default and single change configurations.

\begin{tabular}{|l|lc|ll|}
\hline \multicolumn{3}{|c|}{ Clock constraints } \\
\hline Solution Type & \multicolumn{3}{|c|}{ Intensives } & \multicolumn{2}{c|}{ 24-h sessions } \\
\hline Software & VieVS & Solve & VieVS & Solve \\
\hline Default & none & none & 1.3 & 0.5 \\
Single Change & 1.3 & 1.3 & 0.1 & 0.1 \\
\hline
\end{tabular}




\subsection{Single Change Solutions}

We also looked at the effect of changing single parameters in the solution setup. These changes were all done with respect to the Synchronized solutions. Table 4 displays the differences between the VieVS and solve solutions. Note that with the exception of changing the clock constraint, the effect on the WM and WRMS difference is generally slight, a fraction of a microsecond. Changing the clock constraint has a very large effect. For example, the WRMS difference increases to 28.3 $\mu \mathrm{s}(19.0 \mu \mathrm{s})$ respectively for the Intensives and INT1 sessions, and to $6.7 \mu \mathrm{s}$ for the $24-\mathrm{h}$ sessions. This points to the importance of modeling the clocks correctly, since errors in the station clocks propagate directly into the UT1 estimates.

Table 5 shows the effect of changing single parameters on the difference between the VieVS and Solve estimates of UT1 from the Intensive sessions and that of the external C04 08 series. Table 6 displays the same information for the INT1 sessions. In the VieVS solutions, changing a single configuration parameter has little effect (under $1 \mu \mathrm{s}$ ) except for changing the clock constraint. This significantly increases the RMS scatter, from $\sim 20 \mu$ s to $75 \mu$ s in the case of all the Intensives and to $82 \mu \mathrm{s}$ in the case of INT1 data set. A constraint level of $1.3 \mathrm{~cm} / \mathrm{h}$ is what is normally used in the 24-h sessions without apparent ill effect.

For the Solve solutions, changing a single parameter, including changing the clock constraint, has little effect on agreement with $\mathrm{C} 0408$. We think that the inclusion of the second order term in the clock model for Solve can mimic a rate over a short time period. We also note that the fact that clock constraint does not affect the agreement with $\mathrm{C} 04$ 08 indirectly implies that the increase of the WRMS difference between VieVS and Solve when the clock constraint is imposed must be due entirely to a change in the VieVS estimate.

It is also worth noting that for the INT1 sessions, the agreement between the various VieVS and Solve Solutions (excluding the Clock Constraint solution) and $\mathrm{C} 0408$ is about the same, around $20 \mu \mathrm{s}$. For the Intensive solutions the VieVS WRMS agreement is at the $20 \mu$ s level, whereas the Solve agreement is $22 \mu \mathrm{s}$, indicating that the VieVS results are slightly closer to $\mathrm{C} 0408$.

Table 7 displays the effect of changing single parameters for the 24-h solutions. In general the RMS scatter of the VieVS solutions is $\sim 7 \mu$ s compared to $5.5 \mu$ s for Solve, indicating that Solves estimates agree better with $\mathrm{C} 04$ 08. Focusing on the VieVS solutions alone, the effect of changing most parameters is at the sub $\mu$ s level with the exception of changing the clock constraint, which increases the scatter by $\sim 1.2 \mu$ s. Changing our attention to the Solve solutions, none of the single parameter changes have a significant effect on UT1.

While comparing intensive solutions that both used the FES2004 ocean loading model, we encountered a semi-annual harmonic signal in the difference between the VieVS and Solve UT1 adjustments, Figure 2 (a). After running an intensive solution with tidal ocean loading model FES2004 excluded from both solutions, the signal is not as clearly visible as earlier, Figure 3 (a). Figure 3 (b) plots the dif-
Table 4 : Weighted mean (WM) and weighted root mean square (WRMS) UT1 differences between VieVS and Solve analyses from all Intensives (INT1 through INT3), INT1 sessions only and 24-h solutions. For different solution setups, see Table 2.

\begin{tabular}{|c|c|c|c|c|c|c|}
\hline \multicolumn{7}{|c|}{ VieVS-Solve WM and WRMS differences in $\mu$ s } \\
\hline \multirow[b]{2}{*}{ Solution type } & \multicolumn{2}{|c|}{ all Intensives } & \multicolumn{2}{|c|}{ INT1 } & \multicolumn{2}{|c|}{ 24-h } \\
\hline & WM & WMRS & WM & WMRS & WM & WMRS \\
\hline $\begin{array}{l}\text { Default setup } \\
\text { (no changes) }\end{array}$ & 13.7 & 8.8 & 3.6 & 7.4 & -2.1 & 5.1 \\
\hline $\begin{array}{l}\text { Synchronized } \\
\text { setup }\end{array}$ & 7.8 & 7.1 & 6.0 & 5.2 & -1.7 & 5.5 \\
\hline EOP: C04 08 & 8.6 & 7.3 & 6.8 & 5.3 & -1.3 & 5.5 \\
\hline $\begin{array}{l}\text { Clock } \\
\text { Constraint }\end{array}$ & 9.4 & 28.3 & 6.1 & 19.0 & -1.4 & 6.7 \\
\hline $\begin{array}{l}\text { No } \\
\text { atmospheric } \\
\text { pressure } \\
\text { loading }\end{array}$ & 7.7 & 7.1 & 6.0 & 5.3 & -1.6 & 5.5 \\
\hline
\end{tabular}

Table 5 : UT1 mean formal errors and RMS difference from C04 ( $\mu$ s) for all 2012 Intensive sessions

\begin{tabular}{|l|cc|cc|} 
& \multicolumn{3}{|c|}{ VieVS } & \multicolumn{2}{c|}{ Solve } \\
\hline & $\begin{array}{l}\text { UT1 mean } \\
\text { formal } \\
\text { errors }\end{array}$ & UT1 RMS & $\begin{array}{c}\text { UT1 mean } \\
\text { formal } \\
\text { errors }\end{array}$ & UT1 RMS \\
\hline $\begin{array}{l}\text { Default setup (no } \\
\text { changes) }\end{array}$ & 13.1 & 20.3 & 13.2 & 22.5 \\
\hline $\begin{array}{l}\text { Synchronized setup } \\
\text { mapping function: }\end{array}$ & 13.0 & 20.2 & 13.1 & 22.6 \\
\hline $\begin{array}{l}\text { GMF/NMF } \\
\text { EOP: C04 08 }\end{array}$ & 13.0 & 20.2 & 13.2 & 22.5 \\
\hline Clock constraint & 33.1 & 74.9 & 13.4 & 21.7 \\
\hline $\begin{array}{l}\text { No atmospheric } \\
\text { pressure loading }\end{array}$ & 13.0 & 20.3 & 13.1 & 22.6 \\
\hline
\end{tabular}

Table 6: UT1 mean formal errors and RMS difference from C04 ( $\mu s)$ for 2012 INT1 sessions.

\begin{tabular}{|l|cc|cc|}
\hline & $\begin{array}{l}|c| \\
\text { UT1 mean } \\
\text { formal } \\
\text { errors }\end{array}$ & UT1 RMS & $\begin{array}{c}\text { UT1 mean } \\
\text { formal } \\
\text { errors }\end{array}$ & UT1 RMS \\
$\begin{array}{l}\text { Default setup (no } \\
\text { changes) }\end{array}$ & 14.0 & 20.2 & 14.0 & 20.2 \\
\hline $\begin{array}{l}\text { Synchronized setup } \\
\text { mapping function: }\end{array}$ & 14.1 & 20.2 & 14.0 & 20.2 \\
\hline $\begin{array}{l}\text { GMF/NMF } \\
\text { EOP: C04 08 }\end{array}$ & 14.1 & 20.2 & 14.0 & 20.3 \\
\hline $\begin{array}{l}\text { Clock constraint } \\
\text { No atmospheric }\end{array}$ & 32.8 & 82.5 & 13.9 & 20.2 \\
\hline pressure loading & 14.1 & 20.3 & 14.0 & 20.8 \\
\hline
\end{tabular}

Table 7 : UT1 mean formal errors and RMS difference from C04 ( $\mu$ s) for 2012 IVS R1 and R4 sessions.

\begin{tabular}{|l|cc|cc|}
\hline & $\begin{array}{l}|c| \\
\text { UT1 mean } \\
\text { formal } \\
\text { errors }\end{array}$ & UT1 RMS & $\begin{array}{c}\text { UT1 mean } \\
\text { formal } \\
\text { errors }\end{array}$ & UT1 RMS \\
\hline $\begin{array}{l}\text { Default setup (no } \\
\text { changes) }\end{array}$ & 3.8 & 6.8 & 2.8 & 5.5 \\
\hline Synchronized setup & 3.5 & 7.2 & 2.8 & 5.4 \\
\hline $\begin{array}{l}\text { mapping function: } \\
\text { GMF/NMF }\end{array}$ & 3.6 & 7.6 & 2.8 & 5.6 \\
\hline EOP: C04 08 & 3.6 & 7.4 & 2.8 & 5.4 \\
\hline $\begin{array}{l}\text { Clock constraint } \\
\text { No atmospheric }\end{array}$ & 4.0 & 8.4 & 2.8 & 5.4 \\
pressure loading & 3.6 & 7.4 & 2.8 & 5.3 \\
\hline
\end{tabular}




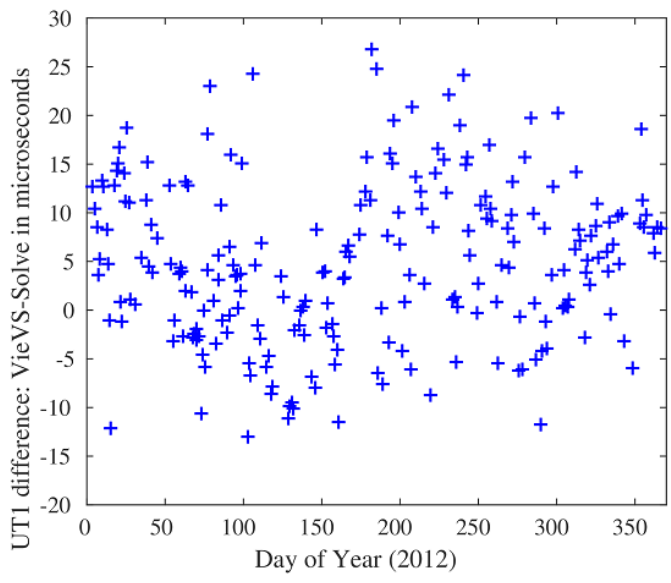

(a) Ocean loading corrections are not reduced from the coordinates of the antennas prior to the parameter estimation.

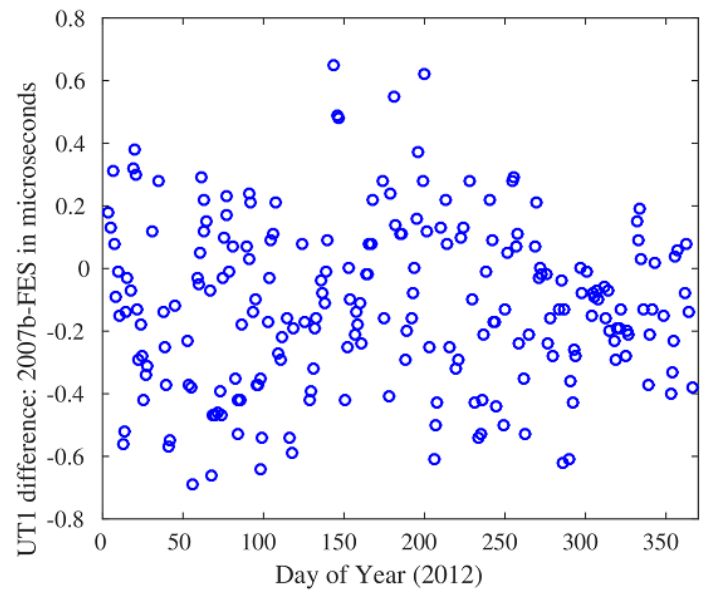

(b) Solve (2007b) - Solve (FES2004)

Figure 3: (a) VieVS - Solve UT1 adjustment differences from the solutions of INT1 Intensive sessions where neither software package used Ocean Loading. (b) Difference between two Solve solutions using different Ocean Loading models.

ference between two Solve solutions which used different ocean loading models. 2007b combines several different models (Agnew 1996, Agnew 1997, Petrov and Ma 2003, Ray 1999). The difference is very slight and does not have a clear harmonic signal. This is evidence that the effect is not caused by ocean loading. We suspect that the harmonic signal is time-tag issue between the software packages, or is related to how the a priori is interpolated.

\section{Conclusions}

One of our goals was to compare the UT1 estimates from VieVS and Solve. We compared the results using the Default setup for both packages except that they both used the same a priori ERP, USNO finals2000A. We ran a second 'Synchronized' solution where the setup was modified as much as possible to be identical, and modest changes were made to the software. In Synchronized configuration both software packages used the same a priori TRF coordinates for TIGOCONC and TSUKUB32, also VieVS used mid-session epochs, and VieVS was enhanced to use baseline dependent weights.

Table 4 indicates that adding baseline dependent weights to VieVS, using the same TSUKUB32 and TIGOCONC coordinates for both software packages, and using mid-session epochs in VieVS synchronized Intensive results significantly, e.g., for solutions including all Intensives WRMS differences of UT1 estimates reduced from 8.8 to $7.1 \mu \mathrm{s}$, and for INT1 solutions from 7.4 to $5.2 \mu$ s. In 24-h solutions the WRMS difference of UT1 worsened slightly from 5.1 to 5.5 $\mu \mathrm{s}$, when the Synchronized setup was used. The WRMS difference is somewhat better than for the Intensives, but a little worse than for the INT1. The difference is slightly larger when compared to the formal errors which are about $4 \mu$ s for VieVS and $3 \mu$ s for Solve. When we used baseline dependent weights to VieVS, the baseline length repeatability WRMS improved in $71 \%$ of the baselines.

We were also interested in how changing solution setup affected the results. To study this we changed the Syn- chronized setup one aspect at a time. In general, the UT1 24-h solution results from VieVS showed more variation than the results from Solve when a single model or parameter was changed. These affects were generally very small (well under $1 \mu \mathrm{s}$ ) with the exception of changing the level of the clock constraint. Changing the clock constraint in VieVS from no constraint to a constraint of $1.3 \mathrm{~cm} / \mathrm{h}$ in the intensive solution, and from 1.3 to $0.1 \mathrm{~cm} / \mathrm{h}$ in the 24 -h solution, had the largest negative impact on both the VieVS results.

During the analysis we noticed a semi-annual harmonic signal in the difference between VieVS and Solve estimates. The origin of the signal is still under investigation.

Comparison of the software packages is highly important to ensure that they work correctly. Furthermore, so is investigating the effect of small changes in the configuration of the software packages to the WRMS differences to ensure producing the most accurate Earth rotation parameters. In the future it would be worthwhile to introduce also elevation dependent weighting (Gipson et al. 2008) to VieVS. It can be noted that using the models described in the IERS Conventions 2010 and used by the software in their default configurations is advisable.

VieVS and Solve are different, but the differences can be easily decreased. The Synchronized configuration significantly reduces WRMS differences for all Intensive sessions and INT1 Intensive sessions. Furthermore, INT1 UT1 RMS and formal errors from the VieVS and Solve software packages agree remarkably well, which implies that the results are consistent.

\section{Acknowledgements}

This work was supported in part under NASA contract NNG12HP00C. The authors are grateful for the reviewer comments which further improved the text. The authors wish to thank Dr. D. MacMillan, Goddard Space Flight Center, for providing information and advice concerning the use of Solve. 


\section{References}

Agnew D.C., (1997), NLOADF: A program for computing oceantide loading, J. of Geophys. Res, vol. 102, pp. 5109-5110, doi: 10.1029/96JB03458

Agnew D.C., (1996), SPOTL: Some programs for ocean-tide loading, SIO Ref. Ser., 96-9, Scripps Institute of Oceanography, La Jolla, 35p.

Bolotin S., (2000), SteelBreeze home page, http://steelbreeze.sourceforge.net. Accessed on 20 March 2015.

Böhm J., Böhm S., Nilsson T., Pany A., Plank L., Spicakova H., Teke K., Schuh H., (2009), The New Vienna VLBI Software VieVS, In: Proceedings IAG Scientific Assembly 2009, In: International Association of Geodesy Symposia Series Vol. 136, pp 1007-1011.

Böhm J. and Schuh H., (2007), Forecasting Data of the Troposphere Used for IVS Intensive Sessions, In: Proceedings 18th European VLBI for Geodesy and Astrometry Working Meeting, 12-13 April 2007, Vienna, pp 153-157.

Böhm J., Werl B., Schuh H. (2006), Troposphere Mapping Functions for GPS and Very Long Baseline Interferometry from European Centre for Medium-Range Weather Forecasts Operational Analysis Data, Journal of Geophysical Research, 111, B02406, doi: 10.1029/2005JB003629.

Böhm J., Niell A., Tregoning P., Schuh H., (2006), Global Mapping Function (GMF): A New Empirical Mapping Function Based on Numerical Weather Model Data, Geophysical Research Letters 33, L07304, doi: 10.1029/2005GL025546.

Dickman S.R., (1993), Dynamics ocean-tide effects on Earth's rotation, Geophysical Journal International, 11, pp 448-470, doi: 10.1111/j.1365-246X.1993.tb01180.x

Engelhardt G., Thorandt V., Ullrich D., (2011), VLBI Analysis at $B K G$, In: Proceedings 20th European VLBI for Geodesy and Astrometry Working Meeting, 29-31 March 2011, Bonn, pp $102-$ 104.

Gipson J., MacMillan D., Petrov L., (2008), Improved estimation in VLBI through better modeling and analysis, In: Proceedings5th International VLBI Service for geodesy and astrometry General Meeting 2008, pp 157-162.

Hobiger T., Otsubo T., Sekido M., Gotoh T., Kubooka T. and Takiguchi H., (2010), Fully Automated VLBI Analysis with c5++ for ultra-rapid determination of UT1, Earth Planets Space, 62, pp 933-937, doi: 10.5047/eps.2010.11.008

Petit G. and Luzum B., (2010), IERS conventions 2010, (IERS Technical Note; 36) Frankfurt am Main: Verlag des Bundesamts für Kartographie und Geodësie, 2010. 179 pp., ISBN 3-89888989-6.

Kantha L.H., Steward J.S. and Desai S.D. (1998) Long-period lunar fortnightly and monthly ocean tides, Journal of Geophysical Research, 103, 12, 639, doi: 10.1029/98jc00888.

Ma C., Sauber J., Clark T., Gordon D., Himwich W.E., Ryan J.W., (1990), Measurement of horizontal motions in Alaska using very long baseline interferometry, Journal of Geophysical Research, 95, B13, 21991-22011, doi: 10.1029/JB095iB13p21991.

MacMillan D., Behrend D., Kurihara S., (2012), Effects of the 2011 Tohoku earthquake on VLBI geodetic measurements, In: Proceedings 7 th International VLBI Service for geodesy and astrometry 2012 General Meeting, pp 440-444, NASA/CP-2012-217504.
Niell A.E., (1996), Global mapping functions for the atmosphere delay at radio wavelengths, Journal of Geophysical Research, 101, 32273246, doi: 10.1029/95JB03048.

Petrov L. and Baver K.D., (2008), Description of the keywords of BATCH control language, 7/31/2008.

Petrov L. and Boy J.-P., (2004), Study of the atmospheric pressure loading signal in very long baseline interferometry observations, Journal of Geophysical Research, Vol. 109, B3. doi 10.1029/2003JB002500.

Petrov L. and C. Ma, (2003), Study of harmonic site position variations determined by very long baseline interferometry, J. Geophys. Res., 108, 2190, doi: 10.1029/2002JB001801.

Plank L., Böhm J., Schuh H., (2010), Comparison campaign of VLBI data analysis Software - First Results, In: Proceedings 6th International VLBI Service for Geodesy and Astrometry 2010 General Meeting, pp 217-221, NASA/CP-2010-215864.

Plank L., (2010), Results from the VLBI data analysis software comparison campaign, Presented at The First VieVS User Workshop, in Vienna, Austria, 2010.

Ray R.D., (1999), A global ocean tide model from TOPEX/POSEIDON Altimetry: GOT99.2, NASA/TM-1999-209478, Greenbelt, 58 p., 1999.

Saastamoinen J., (1972), Atmospheric correction for troposphere and stratosphere in radio ranging of satellites, The Use of Artificial Satellites for Geodesy, Geophysics Monograph Series, Vol. 15. Edited by Soren W. Henriksen, Armando Mancini, and Bernard H. Chovitz. Washington, DC: American Geophysical Union, 1972., p.247.

Saastamoinen J., (1973), Contributions to the theory of atmospheric refraction, Bulletin Godsique, Volume 47,Issue 1, pp.13-34, doi: $10.1007 / \mathrm{bf02522083.}$

Schuh H. and Behrend D. (2012), VLBI: A fascinating technique for geodesy and astrometry, Journal of Geodynamics, Vol. 61, pp. 6880. doi: 10.1016/j.jog.2012.07.007.

Titov O., Tesmer V. and B"ohm J., (2004), OCCAM v. 6.0 Software for VLBI data analysis, Proceedings 3rd International VLBI Service for Geodesy and Astrometry 2004 General Meeting, pp 267271, NASA/CP-2004-212255.

USNO Toshi web site http://toshi.nofs.navy.mil/ ser7/readme. Accessed on 20 March 2015.

Uunila M., Baver K., Gipson J., Nilsson T., (2012), Comparison of UT1 and polar motion from IVS sessions derived from VieVS and solve analysis, In: Proceedings 7th International VLBI Service for Geodesy and Astrometry General Meeting 2012, pp 400-404, NASA/CP-2012-217504.

Wahr J.M. and Bergen Z., (1986), The effects of mantle anelasticity on nutations, Earth tides, and tidal variations in rotation rate, Geophysical Journal of Royal Astronomical Society, 87(2), pp 633-668, doi:10.1111/j.1365-246X.1986.tb06642.x.

Yoder C.F., Williams J.G. and Parke M.E., (1981), Tidal variations of Earth rotation, Journal of Geophysical Research, 86(B2), pp 881-891, doi:10.1029/JB086iB02p00881. 